\title{
Considerações sobre o corpo em Mikhail Bakhtin
}

\author{
Considerations about the body in Mikhail Bakhtin
}

\author{
Marilia Dalva Teixeira'
}

\begin{abstract}
Resumo: Este trabalho tem por objetivo expor como o corpo é apresentado na obra do filósofo russo Mikhail Bakhtin, em especial nos textos $O$ autor e a personagem na atividade estética, Para uma filosofia do Ato Responsável e Cultura popular na Idade Média e no Renascimento: O contexto de François Rabelais. Nesses textos, Bakhtin apresenta o corpo como objeto ideologicamente saturado, quando submetido a movimentos axiológicos da relação entre sujeitos. Esse corpo, possuidor de valor axiológico, depende do outro para se estabelecer esteticamente e pode, na atividade estética, tornar-se manifestação de duas consciências não coincidentes, bem como se apresentar como uma visão de mundo historicamente situada.
\end{abstract}

Palavras-chave: Bakhtin; Corpo; Valor; Alteridade

\begin{abstract}
This work aims to expose how the body is presented in the work of the Russian philosopher Mikhail Bakhtin, especially in texts Author and Hero in the Aesthetic Activity, Toward a Philosophy of the act and Rabelais and his World. In these texts, Bakhtin presents the body as an ideologically saturated object, when submitted to axiological movements of the relation between subjects. This body, which possesses axiological value, depends on the other to establish itself aesthetically and can become the manifestation of two non-coincident consciousnesses in aesthetic activity, as well as presenting itself as a historically situated worldview.
\end{abstract}

Keywords: Bakhtin; Body; Value; Otherness

\section{Introdução}

Em sua obra, Bakhtin observa o corpo para além das características psicofísicas, muito além de um mero aparato biológico, de um objeto científico, a "coisa muda" das ciências exatas. Ele institui ao corpo um valor, isto é, apresenta-o em relação a um sujeito situado em posição única e singular no mundo. Em $O$ autor e a personagem na atividade estética, texto dos anos 20, Bakhtin apresenta considerações sobre o processo constitutivo da personagem, apresentando paralelos entre a vida ética e estética.

Nesse texto, discorre filosoficamente sobre o corpo sem, no entanto, buscar criar teorias sobre ele. Para pensar sobre o corpo, recorre à relação entre o corpo interior meu corpo, pensado de dentro de mim, sobre si mesmo - e o corpo exterior - o corpo do outro, apresentado a mim, situado fora de mim. Associa a essa relação noções basilares que permanecem em seus textos seguintes, como a de exotopia (ou excedente de visão), alteridade, acabamento e ato - algumas delas já apresentadas de modo germinal em Para uma filosofia do ato, seu texto anterior, também dos anos 20. 
Em sua tese de doutorado, publicada posteriormente sob título Cultura popular na Idade Média e no Renascimento: O contexto de François Rabelais, apresenta a noção de realismo grotesco por meio das imagens apresentadas na obra de Rabelais. Nela, o corpo tem a função de converter-se em visão de mundo do homem medieval e renascentista, em sua singularidade e em seu processo de distanciamento da cultura helenística clássica.

\section{O corpo ético e estético e o excedente da visão}

Os universos do homem ético e do homem estético, embora possuam algumas diferenças substanciais, possuem certas semelhanças, pois a arte estetiza a vida e o homem estético é a versão estetizada do homem ético. Ao explicar como se dá o processo pelo qual se dá a construção das personagens, Bakhtin (2003) baseia-se em uma visão perceptória presente no mundo ético para explicar como se dá essa construção e acabamento delas. Para tanto apresenta três categorias de percepção subjetivo-corporal para explicar como nós, enquanto sujeito, compreendemos a nós mesmos e aos outros que nos cercam. São elas as categorias do eu-para-mim, do eu-para-o-outro e do outro-para-mim.

Se considerarmos a categoria do eu-para-mim, ou seja, a forma como me autopercebo, veremos que nossa própria imagem externa, ou seja, os conjuntos de elementos expressivos e falantes do nosso corpo, é experimentada por nós de modo fragmentado, disperso, descontínuo e sem unidade, e apenas internamente. Não experimentamos integralmente a forma como nosso corpo reage a determinadas emoções, pois nossa expressividade não integra nosso campo de visão de modo absoluto. O eu apenas a percebe - e a vivencia internamente. Assim:

[...] minha imagem externa chega ao campo dos meus sentimentos externos, antes de tudo da visão, mas os dados de tais sentimentos não são a última instância nem para decidir se esse corpo é meu; só a nossa auto-sensação resolve a questão. Ela não confere unidade aos fragmentos da minha expressividade externa e os traduz em sua linguagem interna. (BAKHTIN, 2003. p.26)

A minha percepção real apresenta diversas lacunas que não conseguem ser preenchidas ainda que eu busque traduzir minha expressividade na linguagem interna de meu auto-vivenciamento, porque as expressões das minhas emoções e dos meus posicionamentos enquanto indivíduo - minhas reações volitivo-emocionais - são direcionadas a um universo situado fora de mim. Minha imagem refletida no espelho, um autorretrato, uma fotografia, não sou efetivamente eu, mas refrações de mim mesmo que, de nenhum modo, representam para mim a completude de minha imagem externa. Minha própria imagem, conforme Bakhtin, só se constrói a partir da

afirmação volitivo-emocional da minha imagem a partir do outro e para o outro; porque de dentro de mim mesmo existe apenas a minha autoafirmação interna, que eu não posso projetar sobre minha expressividade externa, porque ela se contrapõe a mim no vazio axiológico, na impossibilidade de afirmação. (BAKHTIN, 2003, p. 29).

Ao admirar minha própria imagem no espelho crio virtualmente um outro, capaz de me avaliar esteticamente. Um outro potencial, indefinido, para o qual eu poso e busco encontrar uma posição axiológica sobre mim. No entanto, o que vejo não é minha imagem externa propriamente dita, mas apenas o reflexo dela, uma versão de mim antinatural e pouco produtiva. Um eu inacabado, sem valor e autonomia (BAKHTIN 2003, p. 30-31). $\mathrm{Na}$ autobiografia e no autorretrato, o artista toma posição de autor, fora de si mesmo. Constitui uma nova função, constitui-se como um outro, como um observador externo. 
Busca encontrar um espaço de uma nova consciência, transgrediente a si mesmo. No entanto, de modo diverso, quando meu corpo é apresentado pelo trabalho de um artista, abre-se "uma nova janela para um mundo onde eu nunca vivo" (BAKHTIN, 2003, p. 32), ou seja, um mundo a que eu não tenho acesso senão pelos olhos do outro.

De mesmo modo, o outro assim experimenta sobre si mesmo. Nossos - o meu e do outro - horizontes não são coincidentes quando nos contemplamos. O outro não tem acesso a várias partes de si. Quando observa seu próprio corpo, partes dele são inacessíveis a si mesmo: sua cabeça, seu rosto, sua expressão, até mesmo os limites de seu próprio corpo e as coisas que se encontram além dele. Quando eu o observo, posso enxergar essas partes. Elas se tornam acessíveis a mim. Posso conhecer seu corpo para além do conhecimento que o outro tem de si mesmo. Essa acessibilidade que o outro não possui em relação si mesmo, mas que eu, situado fora dele possuo, Bakhtin chamou excedente de visão ou exotopia. De mesmo modo, esse excedente de visão do outro me auxilia a contemplar o todo da minha diretriz volitivo emocional e de minha posição ético-cognitiva no mundo:

$\mathrm{Na}$ categoria do eu, minha imagem externa não pode ser vivenciada como um valor que me engloba e me acaba, ela só pode ser assim vivenciada na categoria do outro, e eu preciso me colocar a mim mesmo sob essa categoria para me ver como elemento de um mundo exterior plástico-pictural e único. (BAKHTIN, 2003, p. 33).

Esse excedente de nossa visão está atrelado a nossa condição de singularidade e insubstitutibilidade, a que Bakhtin já remete em um de seus textos iniciais como existir-evento, ou seja, a posição única e singular que o indivíduo ocupa na existência (BAKHTIN, 2010).

Quando eu observo o outro - quando entro na categoria do outro-para-mim consigo experimentar a unidade da finitude, confiro acabamento e enformamento a sua imagem: consigo delimitar com o olhar as fronteiras de seu corpo com o mundo, seu limites espaciais, as linhas que emolduram seu corpo etc. Enquanto a mim, não consigo, por questões físico-biológicas, ver meu corpo em sua totalidade. O topo de minha cabeça, meu rosto e o que está para além de mim não me são acessíveis. Deste modo, Bakhtin conclui que "a imagem externa pode ser vivenciada como uma imagem que conclui e esgota o outro, mas eu não a vivencio como algo que me esgota e me conclui” (2003, p. 37). Minha noção sobre o corpo é dada a mim por meio do corpo do outro, pois:

só em relação ao outro eu vivencio imediatamente a beleza do corpo humano, ou seja, esse corpo começa a viver para mim em um campo axiológico inteiramente diverso e inacessível à auto-sensação interior e à visão interior fragmentária. Só o outro está personificado para mim em termos ético-axiológicos. Neste sentido, o corpo não é algo que se baste a si mesmo, necessita do outro, do seu reconhecimento e de sua atividade formadora (BAKHTIN, 2003, p. 48).

Meu corpo não tem valor para mim mesmo, ou seja, eu não posso me posicionar axiologicamente sobre ele. Quem me confere valoração é o outro, por meio de termos axiológicos. Meu instinto de autopreservação acontece independentemente de juízos de valor. Ele não se constitui um ato - para usar termos bakhtinianos - ou seja, é apenas uma reação mecânica, instintiva, que em nada difere do comportamento animal. Meu corpo e minhas necessidades físicas só ganham justificação a partir da relação eu-outro. O outro, em sua simpatia e compaixão, me inscreve axiologicamente no mundo. Para Bakhtin (2003), esse primeiro outro é a nossa mãe, que ao se estabelecer enquanto elo entre nosso mundo interior e o mundo exterior, orienta e organiza hipocoristicamente nosso autovivenciamento.

Como já dito, só a partir do outro, minha própria imagem ganha acabamento e enformamento. Para Bakhtin, "o homem tem uma necessidade estética absoluta do outro" 
(2003, p. 33). Logo, para que um corpo ganhe conotações estéticas, a presença do outro se torna imperativo. Um ator, no momento de sua atuação, cria expressões e movimentos corporais que não podem ser vivenciados por ele externamente, "ele não vê a tensão de seus músculos, toda a pose plasticamente acabada do seu corpo, a expressão de sofrimento do seu rosto, não vê o céu azul contra o qual se destaca para mim sua sofrida imagem externa” (BAKHTIN, 2003).

Ele não tem o poder de conferir acabamento estético no seu desempenho artístico. Os sentimentos que busca expressar externamente são vivenciados por ele apenas internamente e de modo fragmentado. Só através de um processo de co-vivenciamento, de vivenciamento empático com um contemplador, exotopicamente situado, que seus contornos, a movimentação do seu corpo, suas expressões faciais, são estetizados e vivenciados na forma de sentimentos (dor, alegria, tristeza, raiva etc) em plano axiológico. "O artístico é uma forma especial de inter-relação entre criador e contemplador fixada em uma obra de arte" (BAKHTIN, 2003)

A corporificação em Bakhtin é utilizada como meio relativamente simples e eficiente de demonstrar sua concepção de mundo acerca da inacabamento, uma das bases de sua teoria. É aqui que o Bakhtin filósofo encontra o Bakhtin professor que, numa linguagem quase poética, leva o leitor a descobrir, por meio de seu próprio olhar sobre si mesmo, que em sua constituição enquanto sujeito/pessoa é indispensável a participação do outro. A incompletude em que se fundamenta não é apenas teorizada, mas percebida, registrada pelo olhar, sentida em sua complexidade. Assim é, tanto na arte quanto na vida. De modo similar, o filósofo apresenta mais um exemplo de corporificação do ideal de inacabamento: a imagem grotesca rabelaisiana.

\section{O corpo grotesco em rabelais}

No livro A cultura popular na Idade Média e no Renascimento: o contexto de François Rabelais, Bakhtin busca compreender o diálogo entre a linguagem popular e a linguagem oficial existentes na obra de François Rabelais (1494-1553) por meio do contexto em que estava inserida. Tentou analisar a cultura cômica popular, da qual Rabelais seria principal porta-voz, por meio de três categorias: os ritos e espetáculos populares, obras cômicas verbais e formas do vocabulário familiar e grosseiro. Seu intuito era compreender Rabelais em seu mundo, no universo do contexto histórico no qual estava inserido.

$\mathrm{Na}$ obra rabelaisiana, o corpo é constituído pela visão de mundo popular da Idade Média e Renascimento. Seus principais personagens, Pantagruel e seu filho Gargântua, são gigantes cuja boca é capaz de servir de morada a uma aldeia inteira e sua urina capaz de afogar milhares de civis. Seus corpos exprimem o exagero característico do sistema de imagens grotescas. Essa hiperbolização, segundo Bakhtin, não era puramente satírica, mas mantinha profundas relações com a cosmovisão medieval e possuía inúmeras ligações com o seu mundo no qual toda a vida material e corporal é exagerada. A satisfação das necessidades fisiológicas, naturais, do corpo (a comida, a bebida, o sexo) são hipertrofiados e estão em relação estreita com o universo da cultura popular cômica medieval. Aqui acontece um processo de degradação. Não em sentido negativo, mas meramente topográfico. Há uma ligação - positiva - entre a parte inferior do corpo com a terra. O ventre e os genitais estão em relação íntima com os aspectos geradores - e regeneradores - da vida, como a concepção, a gravidez, o parto. O corpo é um princípio básico de comunhão e renovação. Essa concepção difere dos cânones plásticos e literários da estética clássica, que ainda constituem a estética do belo em nossa época: 


\begin{abstract}
Esses cânones consideram o corpo de maneira completamente diferente, em outras etapas de sua vida, em relações totalmente distintas com seu mundo exterior (não-corporal). Para eles, o corpo é isolado, solitário, separado dos demais corpos, fechado. Por isso, elimina-se tudo o que leve a pensar que ele não está acabado, tudo que se relaciona com seu crescimento e multiplicação; retiram-se as excrescências e brotaduras, apagam-se as protuberâncias [...], tapam-se os orifícios, faz-se abstração do estado perpetuamente imperfeito do corpo e, em geral, passam despercebidos a concepção, a gravidez, o parto e a agonia (BAKHTIN, 2013, p. 28).
\end{abstract}

O corpo grotesco está em constante processo de evolução e renovação. Enquanto o corpo clássico tem como características a perfeição, imutabilidade e acabamento, o corpo grotesco está em processo de devir e de inacabamento. Esse corpo tem proporções inverossímeis: são falos gigantes, que excretam rios de urina, capazes de fecundar inúmeras mulheres. É um corpo que se dissolve nas coisas, no ambiente, a ponto de se confundir com elas. É um corpo que é representação da efervescência da multidão:

\begin{abstract}
A atração, própria de todas as pessoas cultas, haverá de comungar na multidão, perder-se na multidão, dissolver-se na multidão, fundir-se com a multidão; não apenas com o povo, mas com a multidão de populares, com a multidão na praça; haverá de entrar na esfera da comunicação familiar específica, fora de quaisquer distâncias, hierarquias e normas, de comungar no grande corpo. (BAKHTIN, 2003, p. 397).
\end{abstract}

Essa fusão, de caráter utópico, seria a grande representação do senso carnavalesco do mundo, ou seja, da característica comum às sociedades, desde a sua mais tenra organização, de criar movimentos contrários à centralização dos discursos oficiais, desconstruindo-os e os reorganizando por meio da inversão e do enfraquecimento de seu caráter autoritário e ameaçador. Para Bakhtin, esse senso carnavalesco teve seu apogeu na durante a Idade Média e o Renascimento e teve como principal expoente na literatura o francês François Rabelais.

Essa concepção de corpo apresentada por Bakhtin vai de encontro ao realismo socialista, estilo artístico oficial do regime comunista defendido por Stalin entre 1941 e 1953 na Rússia (antiga URSS). Nessa linguagem estética, os corpos vigorosos dos proletários, soldados, líderes e heróis nacionais exalavam força, vitalidade e saúde, com o intuito de enaltecer a sociedade recém constituída por meio da representação de jovens saudáveis, fortes e felizes, em cenas populares ou no exercício de atividades laborais (BORTULUCCE, 2008). Trazer à tona essa concepção grotesca constitui uma crítica velada a um sistema de imagens de perfeição e acabamento que filosoficamente era contrário às ideias de liberdade e inovação.

A cosmovisão bakhtiniana sobre a cultura popular em seu caráter utópico traz a essa noção a imensidão e a impossibilidade de delimitar as fronteiras do senso carnavalesco do mundo. Por esse motivo, o corpo grotesco apresenta tantas excrecências e orifícios, pois estes são lugares nos quais "a fronteira entre corpo e mundo se enfraquece" (BAKHTIN, 2003, p. 273), porque são a partir deles que os limites entre dois corpos, ou entre o corpo e o mundo exterior, são ultrapassados, dificultando sua organização e delimitação. Desse modo, o corpo nem sempre é uno, personificado, mas se confunde com o cenário do qual faz parte, funde-se à multidão, torna-se imortal, porque é fruto da História sempre em devir. É um corpo difuso no tempo, que nasce e morre para nascer e morrer incansável e infinitamente.

Um dos exemplos citados por Bakhtin é o das velhas grávidas das figuras de terracota de Kertch, que trazem, em uma só imagem, a gravidez e a velhice, símbolos do início e do final da vida. Dois corpos em um só: um que está próximo ao túmulo, que em breve desaparecerá, carrega dentro de si, um corpo novo, que marca seu renascimento e o ciclo infinito da vida. 


\begin{abstract}
"A imagem grotesca caracteriza um fenômeno em estado de transformação, de metamorfose ainda incompleta, no estágio da morte e do nascimento, do crescimento e da evolução. A atitude em relação ao tempo, à evolução, é um traço distintivo (determinante) indispensável da imagem grotesca. Seu segundo traço indispensável, que decorre do primeiro, é sua ambivalência: os dois polos da mudança - o antigo e o novo, o que morre e o que nasce, o princípio e o fim da metamorfose - são expressados (ou esboçados) em uma ou outra forma” (BAKHTIN, 2013, p. 22)
\end{abstract}

No grotesco as partes do corpo humano ora se fundem a partes de corpos de animais ora se confundem e representam outras partes de si mesmo. O rosto, nariz e boca humanos desempenham o papel mais importante na representação grotesca: a boca sempre escancarada nos remete à figura do banquete, da deglutição hiberbolizada, da sede, da bebida abundante, da comida em excesso. O nariz, por sua vez, sempre representa e substitui o falo, baseado na crença popular renascentista de que o tamanho do nariz é proporcional à dimensão e potência do pênis. Como as imagens dos órgãos genitais são comumente representados de modo exagerado, assim também é o nariz.

\begin{abstract}
As formas da cabeça, das orelhas e também do nariz, só tomam caráter grotesco, quando se transformam em figuras de animais ou coisas. Os olhos não têm nenhuma função. Eles exprimem a vida puramente individual, e de alguma forma interna, que tem a sua própria existência, a qual não conta para nada no grotesco. Esse só se interessa pelos olhos arregalados [...], pois interessasse por tudo que sai, ultrapassa o corpo, tudo o que procura escapar-lhe. [...] Além disso, os olhos arregalados interessam ao grotesco, porque atestam uma tensão puramente corporal. No entanto, para o grotesco, a boca é parte mais marcante do rosto. A boca domina. O rosto grotesco se resume afinal em uma boca escancarada, e todo o resto só serve para emoldurar essa boca, esse abismo corporal escancarado e devorador (p. 276-277).
\end{abstract}

As imagens grotescas, como defende Bakhtin, não estaria relacionada de modo mais forte nas imagens de arte dos povos não europeus, mas estaria também na base do folclore europeu, na linguagem não-oficial e na literatura. Nelas algumas partes do corpo são mais mencionadas que outras: os órgãos genitais, o traseiro, o ventre, a boca e o nariz são sempre citados e modificados. Já os braços, as pernas, rosto (enquanto estrutura) e olhos são pouco mencionados.

\title{
Considerações finais
}

A forma como o corpo é apresentado na obra de Mikhail Bakhtin reflete boa parte de sua filosofia, de sua visão de mundo como lugar aberto, inconcluso, com potencialidade para a liberdade e inovação. A não finalizabilidade é imanente e essencial para a existência humana, pois estamos inseridos no eterno processo em devir. Nada é imutável.

A inconclusibilidade, tão presente em sua obra, representa a liberdade e inovação imanente da vida cotidiana, liberdade essa inseparável da responsabilidade ética, pois na filosofia bakhtiniana não existe álibi na existência, viver é se posicionar axiologicamente: "O pathos da minha vida pequena e do mundo infinito é o pathos do meu não-álibi participativo no existir, e o alargamento responsável do contexto dos valores realmente reconhecidos do meu lugar único” (BAKHTIN, 2010, p. 109).

A imagem grotesca do corpo, como representada na obra de François Rabelais, reflete a liberdade característica do senso carnavalesco do mundo, que dessacraliza e relativiza, que impede que forças centrípetas transformem o mundo em um espaço uno e monológico. 
É este senso um poderoso instrumento contra qualquer monologização da existência humana; é ele que materializa a força cultural do riso: dessacraliza os discursos oficiais, os discursos da ordem e da hierarquia, os discursos do sério e do imutável (FARACO, 2009, p. 80).

Nos dois casos apresentados, o corpo é um aparato ideológico e como ideológico só se constitui na relação entre consciências não-coincidentes. O outro é imprescindível em sua constituição. Apenas por meio deles nos constituímos e somos no mundo. Não existimos sem o outro (sequer temos ideia de como somos sem ele). Só o outro pode conferir o acabamento possível, pode ver-nos em nossa totalidade, de sua posição exotópica. Assim, na filosofia bakhtiniana, na construção de nossa relação com o corpo há a primazia de dois elementos: da liberdade e do outro. Apenas por meio deles, temos consciência de quem somos e de como somos num movimento sem fim, inconcluso, infinito.

\section{Referências}

BAKHTIN, Mikhail. O autor e a personagem na atividade estética in: Estética da criação verbal. São Paulo: Martins Fontes, 2003.

BAKHTIN, Mikhail. A cultura popular na Idade Média e no Renascimento: o contexto de François Rabelais. 8 ed. São Paulo: Hucitec, 2013.

BAKHTIN, Mikhail. Para uma filosofia do Ato Responsável. Tradução de Valdemir Miotello e Carlos Alberto Faraco. São Carlos: Pedro \& João Editores, 2010.

BORTULUCCE, Vanessa Beatriz. URSS, 1925-1939: Da ascensão de Stalin ao início da Segunda Guerra Mundial in: A arte dos regimes totalitários - Rússia e Alemanha. São Paulo: Annablume; Fapesb, 2008.

FARACO, Carlos Alberto. Linguagem \& Diálogo: as ideias linguísticas do Círculo de Bakhtin. São Paulo: Parábola Editorial, 2009. 